\title{
Nursing Workforce Education and Its Implication On Maternal Health In Borno State
}

\author{
Article by Musa James Lassa \\ Msc Nursing, Texila American University, Nigeria \\ Email:musajames61@gmail.com
}

\begin{abstract}
The relationship between nursing and maternal health presents a legitimate policy discussion. In this qualitative descriptive study, the views of nurse experts on the current status of nursing and midwifery education, and workforce development issues as they relate to maternal health in Nigeria was explored. Focus was on experts as they constitute important players in policy decisions related to nursing workforce and maternal health services delivery. Qualitative content analysis was used to analyze interview data. The findings of this study indicated that nursing and midwifery schools utilize a rigorous curriculum mandated by the Nursing and Midwifery Council of Nigeria (NMCN). It was also found that nursing workforce development is plagued by pedagogical issues, gender issues, and multi-faceted health systems challenges. These findings suggest that Nigerian nursing workforce is highly unstable and broader policies on workforce training, recruitment and retention are needed to improve maternal health outcomes.

Key words: Nursing education, midwifery education, nursing workforce development, health policies, maternal health, Nigeria.

\section{Introduction}

Nurses in Nigeria play significant roles in maternal health services provision. The high levels of maternal mortality ratio (MMR) in Nigeria, estimated at 630 per 100,000 live births (WHO, 2011), is an indicator of serious maternal health needs. Recruitment and retention of appropriate number of health personnel, particularly trained nurses and midwives (the core of health services delivery in Nigeria) are crucial for maternal death reduction. Although Nigeria has a relatively high number of nursing personnel (a pool of 210,306 nurses compared to other African countries) (WHO, 2009), there is still a significant shortage of nurses that are required to meet the health needs of a country of over 160.7 million people (WHO, 2013) that lags in positive maternal health outcomes. With a population of 4.2 million people (Borno State Government, 2011a); Borno state is one of the densely populated States in Nigeria with an estimated 1,500 to 2,000 persons living within every square kilometer (Borno State Government, 2011b). Women make up 53\% of this population (National Bureau of Statistics, 2012). Evidence shows that as the density of health workers increase, maternal mortality falls; and a 10 percent increase in the density of the health workforce correlates with about a 5 percent decline in maternal mortality (The Joint Learning Initiative (JLI), 2006).
\end{abstract}

\subsection{Rational of the study}

The purpose of this study is to describe the system of nursing and midwifery education, the challenges to nursing workforce development and their impact on maternal health in Borno State, Nigeria.

\subsection{Significance of the study}

This study is design to look at nursing educational workforce challenges towards maternal health. The study will in one way or the other, proffer solution to improve the quality and quantity of nursing services towards maternal health. It is also expected to provide additional awareness to nurses to further their education. It may also be valuable for interested researchers to formulate and implement some new polices on nursing education and their 
South American Journal of Nursing

Special Edition 2016

workforce development, with a view to minimize nurses migration.

\subsection{General and specific objectives of the Study}

\subsubsection{General objective}

The objectives of the study were to access the system of nursing and midwifery education as related to its workforce development towards maternal health in Borno state, Nigeria.

\subsubsection{Specific objectives}

1 To find out how nurses and midwives educational qualification would reduce maternal mortality rate.

2 To find out if increase in density of nurses and midwives workforce help reduce maternal mortality rate.

3 Find out measures to retain and recruit appropriate numbers of nurses and midwives.

\subsection{Hypotheses/Research questions}

1 There is no significant relationship between nursing workforce and educational development.

2 There is no significant difference between nursing staff motivation and workforce.

3 There is no significant relationship between workforce and maternal mortality rate in Borno state, Nigeria.

\subsection{Operational definitions}

1 Nursing education: -Knowledge of professional task towards looking after people who are sick or injured by nurses.

2 Midwifery education: -Knowledge of the technique or practice of helping to deliver babies and offering advice and support to pregnant women.

3 Nursing workforce: -The physical or mental effort directed at completing nursing function or carrying out nursing task.

4 Nigeria: -Country in West Africa, official name Federal Republic of Nigeria.

5 Maternal health: -General condition of the body in terms of presence or absence of illness relating to motherhood.

\section{Review of literature}

Studies also show that countries with more nurses per proportion of the population have less maternal deaths than those with fewer nurses (Shiffman, 2007; Buor and Bream, 2004; Bulatao and Ross, 2003). For example, United Kingdom and United States have nurse density to population ratios of 12.12 and

9.37 per 1,000 , respectively, while Nigeria has only 1.7 per 1,000 (WHO, 2006). United Kingdom and United States also have corresponding MMR of 12 and 21 per 100,000 live births, respectively, while Nigeria has a MMR of 630 per 100,000 live births in 2010 (WHO, 2011).

Chankova et al. (2006) estimated that there were 122,000 nurses and midwives in the public sector in 2005 and for Nigeria to meet the health-related MDGs, it would need 157,315 public sector nurses and midwives by 2015 (a deficit of about 39,880 taking the annual population growth into consideration).

Nurses are the backbone of maternal health services delivery. Emphasis on nursing and midwifery education, recruitment, and retention is therefore important in pursuing efforts to improve maternal health. Nigeria is among 57 countries (36 in Africa) that lack the critical mass of health workers necessary to meet the health-related MDGs (WHO, 2006). Nurses are important part of the health workforce as they constitute 45 to $60 \%$ of the entire workforce in sub-Saharan Africa (Dovlo, 2007).

Furthermore, staff nurses and midwives direct and provide most obstetric care more than any other providers, and they are highly preferred in Nigeria (Ezeonwu, 2011). However, 
nursing education and workforce development had been beset by multiple challenges including health systems issues, and various structural push and pull factors that drive migration (Hagopian et al., 2005; Gerein et al., 2006). Several evidence indicated continuous hemorrhaging of the nursing workforce. For example, between 2004 and 2007, 16,383 nurses sought employment outside Nigeria (Labiran et al., 2008). As of 2007, twenty-five international recruiting firms were still recruiting from Africa and seven of those firms were active in Nigeria (Pittman et al., 2007).

WHO (2006) estimates that about $3 \%$ of the nursing workforce $(5,375$ nurses) in Nigeria was registered in Organization for Economic Corporation and Development (OECD) countries in 2006. A 3\% loss appears minuscule but could translate into zero nurses for millions of Nigerians based on the WHO's estimation of nurse-to-population ratio of 1.7 nurses per 1,000 population. Dovlo (2007) concurs that even minor losses of nurses to migration will magnify the existing shortages in sub-Saharan African countries. Furthermore, the effect of each loss is significant, considering the length of time and resources it takes to train a nurse and the country's high maternal mortality rate. These factors are broad and include the health system's inability to create jobs and absorb nurse graduates, debilitated infrastructures, poor remunerations, poor working conditions, and occupational risk exposures that push the employed out and away from the system.

People migrate for a variety of reasons: to escape oppressive political climates, to pursue better economic opportunities for themselves and their families, to better their education or those of their children, or even just for adventure (Kingman, 2011). Nurses want access to resources so that they can learn and practice in a better way. Some migrate to be more autonomous. Other still just doesn't find the employment opportunities in their own countries (Kingma, 2011).

Despite most people would prefer to remain in their home countries, there are a series of 'pull' and 'push' factors that motivate a person to leave home and family to pursue other opportunities. Other factors play a key role in "pushing" nurses out of their home country including an unsafe work environment, lack of political stability, high workloads, or lack of economic remuneration. The "pull" factors address some or all of those concerns and promise a better situation elsewhere.

In some countries nurses work full time and still earn a salary below the poverty line (Kingman , 2011).Many of these nurses are also single parents and when you're faced with not only the financial needs of your children or perhaps elderly parents or even siblings, those financial constraints can become enormous.

Unemployment is very common among nurse professionals in Nigeria in the midst of acute nursing shortage. Schools continue to graduate a good number of nurse professionals, many of whom are either unemployed or underemployed (Chankova et al. 2006). Nigeria produces an estimated 5,500 nurses per year; however, only 1,331 are absorbed by the public health sector. The high number of unemployed nurses does not imply overproduction or "excess supply" in a country of over 160.7 million people, but a failure of the government to effectively manage its most critical labor force through recruitment, strategic distribution and retention (Olabode, 2012).

The efficiency of the Nigerian health care system stagnated over the past decades due to the impact of the International Monetary Fund's structural adjustment program, a reform policy to promote fiscal responsibility and stabilize the economy (Awofeso, 2010). These fiscal austerity measures imposed by the international financial agencies are important contributory factors to the health system's failures. (Dovlo, 2007). Fiscal restraints imposed by international loan conditional ties cause countries to freeze employment and retrench workers, particularly in the public sectors, making it hard for those countries to expand their workforce significantly even when supply is available. Training, successful recruitment and retention of nurse professionals in Nigeria will involve strategic efforts to address underlying structural health systems issues that negatively affect nursing and health outcomes for mothers, from the academic institutions to the points of care delivery (Olabode, 2009). These 
result in shortage of nurses who are actively engaged in providing health services in the country. Although Nursing and midwifery education in Nigeria have continued to evolve, the Nursing and Midwifery Council of Nigeria (NMCN), a parastatal of the Federal Government of Nigeria and the only professional regulatory body for all cadres of nurses and midwives in Nigeria (NMCN, 2007), which strives to upgrade and standardize the nursing and midwifery programme curriculum.

The path to higher degree is still complicated for Nigerian nurses; nurses have to go through routes that are not clearly defined to obtain higher qualifications. Nursing education at the baccalaureate level and beyond is still not popular and only offered by few universities in the country (Ndatsu, 2011). For example, of the 124 federal, state and private universities approved by the National Universities Commission (NUC) in Nigeria (NUC, 2012), only four universities have fully accredited departments of nursing; eleven universities have provisional accreditation status; and one of these eleven schools is located in Borno State (NMCN, 2010). Despite the slow movement toward university-based program, and the many logistical challenges, the schools engage in strong and competitive curriculum and produce different cadres of competent practitioners in the country.

\section{Methodology}

The chapter deals with the research design which includes the target population; sampling technique, interview, administration and collection of information from respondents.

\subsection{Design of the study}

A qualitative, descriptive, cross-sectional, survey was used to assess the situation of nursing workforce education and its implication on maternal health in Borno state. This design will elicit the current nursing education of nurses and midwives workforce and determine various factors responsible for the shortages, migration, and low pursue of nursing education.

\subsection{Study area}

This study will be carried out in Borno state, Nigeria. It will be conducted in university of Maiduguri, state school of nursing and midwifery, hospitals management board headquarter, and nursing and midwifery council of Nigeria, Borno state.

\subsection{Study population}

The population of study consists of twenty-four (24) nurses from various areas from Borno state. Based on the number of nurses used for the study, six staff nurses and midwives with certificate in general nursing; four midwives with diploma in midwifery education; four nurses with bachelor degree in nursing and midwifery education; two with masters in nursing education; two with masters in nursing administration and management; and two with masters in educational planning and policy.

\subsection{Study duration}

The total time period required for completion of the study from day of conception to submission of project, based on series of activities is six months. Activities involving drafting of concept, drafting and revision of proposal, data collection and analysis, various corrections from co-guide and other researcher assistants. Activities commenced in the month of October through the month of March.

\subsection{Sample method}

The researcher is using the sample subject of twenty-four (24) and will make use of random sampling method

\subsection{Sampling size}

A convenient sample size of twenty-four participants was recruited for this study, and 
simple random sampling technique was employed for selection through interview of nurse experts at different institutions.

\subsection{Sampling technique}

This sampling was heavily influenced by accessibility factors such as the insurgency (boko haram), weather, and transportation (road conditions) during the study period. Four of the participants were members of the top management staff of the NMCN. Ten were nurse educators, with the job title of "principal" or "director" of their respective nursing or midwifery schools. Ten were health administrators, and they direct nursing care services at their respective hospitals.

\subsection{Pretesting}

Personal interview carried out in a structured interview, which involved use of a set predetermined question and of highly standardized techniques of recording among randomly selected six nurses. Cooperation gained furthered better chance to conduct the research work proper.

\subsection{Method of data collection}

Participants were interviewed in their offices at their respective institutions. This study was conducted primarily in Borno State, Nigeria. However, participants affiliated with the Nursing and Midwifery Council of Nigeria was interviewed at their respective offices located in major cities outside Borno State. The nurse educators were interviewed at their respective academic institutions. The nurse administrators were interviewed at their respective hospitals.

\subsubsection{The general inclusion criteria include:}

(1) All participants must be over 18 years of age, (2) they must speak and understand English, (3) the management staff of the NMCN must be active representatives of the governing body of the Council, (4) the nurse educators must direct their nursing and midwifery schools, and (5) the hospital administrators must direct the relevant health facility. All participants were high-level administrators who influence policy decisions in their respective institutions and impact nursing workforce development and women's health in the country. Each of the participants has extensive practice, teaching, and leadership and management experiences. Hitherto, under-aged, retirees and inactive rural nurses and midwives were excluded.

\subsubsection{Data collection}

Participants were identified by physically walking into the facilities and obtaining the names of the potential participants who met the inclusion criteria. Arrangements for interview appointments were not possible prior to each encounter, as attempts to contact potential participants through regular contact protocols including telephone, fax, and e-mail, were unsuccessful due to communication and accessibility difficulties, bomb explosions and road blocks from security outfits. Face-to-face, on-the-spot recruitment at different institutions was done. There was no official schedule for the meetings. Each participant was approached and given detailed information about the study and the procedures. All their questions were answered. Written informed consent was obtained from each participant and interview arrangements were made. Interview questions focused on admission, training and graduations processes, challenges to nursing and midwifery workforce development, and their implications on maternal health. The interviews were semi-structured, lasted twenty-five to sixty minutes, and were audio-recorded. Interviews included open-ended questions. Examples of questions included: (1) what are the nursing and midwifery admission and graduation processes and requirements in Nigeria? (2) What in your view are the current issues and challenges related to nursing workforce development in the country? (3) How does the availability of adequately trained midwives affect maternal health services provision in Nigeria? Four participants declined audio recording of their interviews; however, detailed 
South American Journal of Nursing

Special Edition 2016

notes were taken. All data collected were coded appropriately. Three senior researchers from the author's institution reviewed and concurred with the coding process.

\section{Presentation of results}

\subsection{Data analysis}

Analysis of data from face-to-face interviews and field notes was done to provide a clear qualitative description of the participants' perspectives on the status of nursing education and workforce issues within Borno state of Nigeria.

The interviews were transcribed verbatim by the researcher. Transcripts of data were confirmed and manually analyzed using qualitative content analysis procedures and processes outlined by Graneheim and Lundman (2004) and Elo and Kyngas (2007). The text was read through by the researcher from beginning to end several times. Texts of recorded interviews of participants regarding their views on nursing education and workforce issues constitute the units of analysis for this study. Themes and subthemes that account for all the data in the interview transcript related to nursing education, workforce challenges and maternal health emerged from this reduction process and constitutes the findings of this study.

In view of the above selected interviewed respondents, the research questions are presented in tables as below:-

Research question I: there is no significant relationship between nursing workforce and educational development.

Specific objective 1: To find out how nurses and midwives educational qualification would reduce maternal mortality rate.

Table I: Percentage of nurses' educational qualifications.

\begin{tabular}{|l|l|l|l|}
\hline $\begin{array}{l}\mathrm{S} / \\
\mathrm{N}\end{array}$ & Nurses educational qualifications & $\begin{array}{l}\text { NO } \\
\text { respondents }\end{array}$ & $\begin{array}{l}\text { Percentag } \\
\text { e }\end{array}$ \\
\hline 1 & Staff Nurse and midwifery certificate & 6 & $25 \%$ \\
\hline 2 & Diploma in midwifery education & 4 & $16.7 \&$ \\
\hline 3 & Baccalaureate in nursing and midwifery education & 4 & $16.7 \%$ \\
\hline 4 & Masters in public health and nursing administration and & 2 & $8.3 \%$ \\
\hline 5 & $\begin{array}{l}\text { Masters in } \\
\text { management }\end{array}$ & 2 & $8.3 \%$ \\
\hline 6 & Masters in public administration & 2 & $8.3 \%$ \\
\hline 7 & Masters in educational planning and policy & 2 & $8.3 \%$ \\
\hline 8 & Masters of science in nursing education & 0 & $8.3 \%$ \\
\hline 9 & PHD & 24 & 0 \\
\hline & TOTAL & $100 \%$ \\
\hline
\end{tabular}

Source: Field Survey, 2014.

$25 \%$ respondents have the highest number of nurses with general nursing certificates, while the least percentages of $8.3 \%$ representing masters in various discipline. This represents less than $50 \%$ of significant value. Hence, the hypothesis is accepted.

Research question II: there is no any significant difference between workforce and nursing motivation?

Specific objective II: Find out measures to retain and recruit appropriate numbers of nurses and midwives.

Table II: predisposing factors to nurses migration.

\begin{tabular}{|l|l|l|l|}
\hline S/N & Options & Respondents & Percentage \\
\hline 1 & Poor remuneration & 16 & $66.7 \%$ \\
\hline 2 & Poor condition of service & 6 & $25.0 \%$ \\
\hline 3 & Occupational risk & 2 & $8.3 \%$ \\
\hline TOTAL & 24 & $100 \%$ & \\
\hline
\end{tabular}


Source: Field Survey, 2014.

$66.7 \%$ representing 16 respondents indicates that poor remuneration is suggestive of nurses' migration. This hypothesis is therefore rejected.

Research question III: there is no relationship between nursing workforce and reducing maternal mortality rate.

Specific objective III: To find out if increase in density of nurses and midwives workforce help reduce maternal mortality rate.

Table III: representing nurses and midwives role in reducing maternal mortality rate.

\begin{tabular}{|l|l|c|c|}
\hline $\mathrm{S} /$ & Options & $\begin{array}{l}\text { Respondent } \\
\mathrm{N}\end{array}$ & \multicolumn{2}{l}{$\begin{array}{l}\text { Percentage } \\
\mathrm{s}\end{array}$} \\
\hline 1 & Conducting deliveries and care during peurperium & 12 & $50 \%$ \\
\hline 2 & $\begin{array}{l}\text { Inserting uterine contraceptive devices and prescription } \\
\text { of oral pills }\end{array}$ & 12 & $50 \%$ \\
\hline & TOTAL & 24 & $100 \%$ \\
\hline
\end{tabular}

Source: Field Survey, 2014.

$50 \%$ of respondents is considered significant base on this study; hence, the hypothesis is rejected.

\subsection{Observations and findings}

The system of nursing and midwifery education in Nigeria influences nurses' broader responsibilities. The findings of this study showed that nurses go through a rigorous integrative curriculum in order to get licensed. The curriculum discussed in this research is reflective of the basic and general nursing and midwifery programs since university-based programs that could produce master and doctorate level graduates are still emerging. Although general and basic program graduates are skilled and do bits of everything, their earned non-degree diplomas and certificates limit their capabilities in the field. Majority of the nurses are locked into clinical practice through their educations and training in the basic nursing and certificate programs. This presents roadblocks for professional advancement to higher level leadership and policy positions; and to compete with their peers in other healthrelated fields such as medicine and pharmacy.

These findings are consistent with an earlier report by Munjanja et al. (2005) that preparation of nurses in African countries has been more for clinical systems management than for strategic policy development. Efforts toward advanced nursing education should be unrelenting as policy decisions related to maternal health issues should be spearheaded by nurses and midwives. They deserve strategic positions of leadership in academic, policy, and higher-level health services administration in Nigeria.

This study revealed that the lower social position accorded to women impacts policies related to nursing education and practice in Nigeria. This may not be surprising considering the nation's paternalistic culture. In Nigeria, men dominate all spheres of women's lives, and the social relations and activities of women are governed by patriarchal systems of socialization and cultural practices which favour the interests of men above women (National Coalition on Affirmative Action (NCAA), 2009). The domination of the nursing profession by women and medical profession by men explains in part the unequal political landscape that is evident in clinical practice settings. Ndatsu (2004) and Olade (1996) concur that the subordinate role of the nurses in relation to physicians indoctrinated in early nursing education in the country intensifies this problem.

In this descriptive study, qualitative content analysis was utilized to analyze the views of nurse experts in Borno State, Nigeria on the current status of nursing and midwifery education, and nursing workforce issues as they relate to maternal health. Specific interview data collected include admission and graduation requirements of the nursing and midwifery schools, theoretical and clinical training, workforce development challenges and their implications for maternal health services provision and utilization. 
South American Journal of Nursing

Special Edition 2016

\subsubsection{Admission}

Admission requirements to the schools of nursing and midwifery were described by the participants as strict in comparison to schools of medicine and pharmacy, because of quota systems used for admission criteria. General nursing and midwifery programs are common. All programme admission requirements were mandated by the Council. Each school of nursing and midwifery represented by the educators in this study admitted a maximum of 60 students per calendar year, as allowed by the Council. The post-basic midwifery program admits a maximum of 30 students per calendar year. Data on graduate programs (master's and doctorate) were not obtained. They pointed out that all nursing and midwifery institutions in Nigeria undergo reviews and re-accreditations by the Nursing and Midwifery Council. When significant problems are identified through the reviews, student intake is suspended until programme deficiencies are rectified. Four of the participants confirmed that intakes of students at their respective schools were at some point suspended while they instituted remedial activities in order to graduate their backlog of students. Information on the regularity or frequency of such reviews was not obtained for this study.

\subsubsection{Training}

The educators emphasized that formal lectures and clinical instructions in the field constitute the core curriculum. They explained that the NMCN develops the framework, and sets the programme standard for schools. The framework determines the sequence of specific courses required in the nursing and midwifery curriculum. The Council's comprehensive curriculum integrates classroom lectures, practical demonstrations in the laboratories, and clinical experiences at health facilities including primary care settings and hospitals. Basic and general nursing training programs produce versatile and well-rounded nurses who do bits of everything such as general nursing, psychiatry, education, administration, public health, and midwifery. Midwifery programmes further prepare students to perform physical examinations and health needs assessments; palpation, early detection of abnormal risk factors and timely referral, labor, delivery, and child welfare including nutrition, growth monitoring, and immunization. The theoretical and clinical components of the curriculum, according to the participants help prepare the students to be competent nurses and midwives.

\subsubsection{Theoretical preparation}

Findings on the theoretical preparations showed that students were equipped with the fundamental knowledge of nursing and midwifery. The curriculum includes extensive and rigorous coursework that exposed students to the use of the nursing process in the care of individuals, families, and communities. Basic and general nursing training programmes emphasize human anatomy, physiology, and fundamentals of nursing and midwifery practice, but also reproductive health, including family planning, infant and child health. The midwifery programme also embraces a rigorous curriculum according to the participants. The programme has extensive course work including applied anatomy and physiology, with emphasis on midwifery (an important course that supports the midwife's role in understanding physiologic changes during pregnancy, and locating the female anatomical landmarks during delivery). After examples of other courses include; fundamentals of midwifery practice, community-based midwifery practice, family planning, ethics in midwifery, and research methods and statistics. Seminars in midwifery practice provide students with opportunities to practice presentation techniques in giving health and antenatal talks to different audiences. Students are also prepared for physical examinations and health needs assessments. Theoretical foundation on family planning, abortion and post-abortion care, and pharmacology related to obstetric practice also command emphasis in the classrooms, according to the participants.

\subsubsection{Clinical training}


The participants emphasized the importance of integrative curriculum by explaining that theoretical learning supports and reinforces clinical training in skills related to patient monitoring, stages of labor, actual birthing processes, and postpartum care. Students are posted to both antenatal community clinics and antenatal wards in the hospitals. These settings provide students with opportunities to observe and actually assist in clinical activities. The educators reported that in the field, students work under the supervision of public health nurses, staff nurses, midwives, and their clinical instructors. One participant noted that practical exposures hold the key to students' achievement of their competency goals in birth attendance, postpartum care, placement of contraceptive devices, and other important obstetric and gynaecologic clinical activities. For example, before sitting for the qualifying examination for licensure, students in the post basic midwifery program are required to have done a minimum of 30 deliveries, cared for 40 or more clients during peurperium, inserted minimum of 10 intra uterine contraceptive devices, fitted 2 diaphragms, prescribed 15 oral contraceptives, and performed at least 5 manual vacuum extractions. These are stipulated by the NMCN. Participants explained that theoretical knowledge gained in the classroom supports students' experiences in the real world.

\subsubsection{Graduation}

The findings showed that the number of students that graduate each year are variable and depends on students' academic performances, levels of clinical competencies, and skills acquisition. Evaluations of students under these criteria were conducted by the academic staff, field preceptors and clinical instructors. One participant described their graduation requirements this way:

'Students' assessments and evaluations are based on their continuous progress in the program, after the introductory block, semester examinations are given by the respective schools, and the Council's qualifying final examinations."

Registration and licensing follow successful completion of the program.

\subsection{Challenges to nursing and midwifery workforce development}

\section{Pedagogical challenges}

This study showed that unavailability of teaching resources greatly impacts the teachers' abilities to teach. Lack of basic educational items that facilitate teaching and learning hinder efforts on nursing workforce development. Such items include academic journals, books, projectors, computers, and laboratory and demonstration equipment such as midwifery kits. Others include office supplies such as papers, ink, printers, copiers, and telephones. One participant talked about books and electronic materials and stated:

"Most of the books that are reasonably written are American or British-based. We don't have too many African authors and Nigerian authors, or books contextualized to the health problems of our population. We have just started making use of the internet but we are not able to subscribe or pay in order to access new online research or teaching materials."

\section{Financial constraint}

Furthermore, many current and prospective students find it difficult to meet the financial obligations of nursing and midwifery schools, making it difficult for qualified individuals to start and complete their education. One participant said:

"Most students that come to our school are from poor families. One of them now is qualified but not able to pay 'kobo' (local currency denomination equivalence of one cent or less)."

Such students are unable to pay their tuition or acquire the required books and other items needed to complete their programs successfully.

\section{Gender issues}

Participants noted that Nigeria is a paternalistic society and issues related to gender affect nursing as a profession. At the familial level, there is lack of spousal support as some men do not allow their wives to reach their maximum academic potential. One participant put it this 
way:

"Some women are capable, but the type of 'Nigerian mentality' men we marry - they won't even allow you to go to school or further your education. They feel that when you come back, you become the master of the house."

Few participants expressed optimism that things will change in relation to family dynamics in favor of women, and their potential in pursuing academic careers such as nursing. Nursing remains a profession with the greatest proportion of women in Nigeria, and as such, participants believed that policies related to nursing are not taken seriously by the government, compared to other professions such as law or medicine. Data on gender ratio in the nursing workforce were not obtained for this study.

\section{Certification}

Participants agreed that the multiple certifications in nursing provide no benefit to nurses in terms of ascending the career ladder in leadership roles such as in education and administration, since the certificates are not recognized by the universities. One educator expressed deep frustration about the poor recognition accorded to nursing qualifications:

".... the certificates, a whole staff nurse midwife, you get your midwife certificate and it is not even a diploma. It does not belong to diploma; neither does it belong to a degree." It has no define academic classification in certification.

\section{Practicum}

Nurse educators and their students experience practice handicaps during their practicum as more attention is paid to resident doctors and medical students. One participant used the word 'red tapeism' to describe this situation. For example, student nurses are often not allowed to perform key obstetric functions when there are medical students or resident doctors in the wards that also needed the experiences. She explained that nurses are often not given full practice opportunities particularly in tertiary facilities, thereby limiting their prospects for learning and professional growth. The subordinate role of nurses and lack of respect for the profession in the context of gender differences affect the image of the profession. A participant stated:

".... but you know, in Nigeria, the women, the stigma, the high position accorded to men and doctors from the colonial days still obtains."

\subsection{Health system's challenges}

Participants attributed most problems confronting nursing workforce development to Nigeria's weak health system such as inadequate physical and human infrastructures, fiscal constraints in absorbing trained nurses, and poor salaries. Students and staff are squeezed into tight classrooms and office spaces, creating teaching and learning challenges. They emphasised that schools of nursing and midwifery do not get significant financial support from the government and mission schools and hospitals in particular are heavily affected. These mission institutions were established by British missionaries many decades ago, resulting in numerous dilapidated infrastructures that are never upgraded or equipped. They lack critical resources for effective teaching and learning, and most importantly fail to attract young people. They are therefore financially dependent on tuition and local churches whose memberships include the very poor in rural villages. One participant simply stated:

"We have no money to run our academic institutions." Another stated, "They (people in government) need to realize that we are part of this country and we are doing good service to humanity. They should help us and give us grants to train many more nurses... equip the wards and the training areas. If they can help us, it will be nice, because where there is money there is everything, and where there is will, there is hope".

Participants noted that despite tough challenges, schools continue to train and graduate a good number of nurses and midwives even though the jobs are not always there. They acknowledged that it is difficult to witness high nursing unemployment in the midst of surging maternal health care needs. They explained that the government often places embargo on employment because it lacks the fiscal resources to create health care jobs, leaving many 
highly qualified nurses and midwives unemployed in a society that is in dire need of their services. Information on specific dates of embargo on jobs in Nigeria was not provided by participants in this study. A participant believed that many highly qualified nurses are produced each year that they could meet a significant proportion of the health needs of the country. Unfortunately, significant numbers of them are unemployed, and those who are employed are unhappy and eventually leave. Poor remuneration was repeatedly pointed out by all participants as one of the biggest impediments to the growth of the profession and workforce development. Employed nurse educators get low salaries and go unrewarded for most of the work they do. They explained that with the meager salaries, they could not afford continuing education through conferences and workshops, or attain higher degrees to advance their careers in addition to meeting their basic family needs. Furthermore, delayed promotions and inadequate compensations create frustrations and affect the morals and performances of nurses, thereby causing them to consider alternative options. One participant put it this way:

"We have nurses and midwives that are skilled ... the unfortunate thing is that nurses overall are not favored in Nigeria because of the pay. Remuneration is very low, so they keep leaving the country to South Africa, America and even Cameroun, neighboring country. Participants noted that although graduates could be employed in variety of positions, first and second tier jobs (federal and state agencies) are preferred but highly competitive, and therefore not readily available. Private hospitals absorb significant number of graduates despite their very low remuneration. Some of the participants' who are working in Government Hospitals also work with private Hospitals for part time to augment their remuneration.

"They do not want to pay them well, but rather saturate their hospitals and clinics with those who dropped out of school because they failed in the programme and are therefore, not licensed to practice".

For qualified nurses, one participant stated: “The nurses' graduate, and we throw them into the job market where there are no jobs. Some nurses find themselves in the private hospitals where they 'use them' because you cannot imagine that the staff nurse midwife would be paid between 4000 and 7000 naira (approximately $\$ 30$ to $\$ 50$ ) per month".

Another participant expressed dissatisfaction about the uncertain future for new graduate nurses by summing it up this way,

“... We are throwing them out in the job market. Some going to South Africa, some going to Tanzania, all these places, go all over the world, you see Nigerian nurses. Because they cannot get employment in Nigeria, and when they have the employment, the pay is weaker, otherwise if you are well paid, how can you leave your family in Nigeria and go abroad?"

Nigerian nurse and midwife graduates, according to participants, are highly interested in overseas employment, particularly in the United States. They were concerned about the high number of nurses who are leaving the country to unknown destinations. Participants stated that they do not keep any data on their employees' or graduates' whereabouts after they leave their jobs or the schools. However, the educators reported an increasing trend in the number of transcripts requested by their graduates. One participant said:

"This year, of all the 29 that qualified and graduated, we confirmed that five midwives have already left the country (within six months of their graduation)."

A participant commented that many Nigerian nursing students have no zeal anymore to study and learn contextual clinical issues, with the plan of practicing within the country postgraduation. They study with the intent to migrate overseas. The participant stated:

"They are just in to 'pass examinations'. It has not been like that all this time. We used to have students who are committed and know what they are doing. I don't know whether it is this 'American check-out' that is causing this because all they do now is to pass exam and then take the Commission on Graduates of Foreign Nursing Schools (CGFNS) certification examination."

Another participant noted that the United States and United Kingdom opened their doors for Nigerian nurses, but their activities are definitely a problem for Nigeria. "We do however, 
encourage and welcome our nurses to go and train abroad, where there are better opportunities for them to learn, and then come back to teach here in our nursing and midwifery schools. That does not happen. That's the problem."

New and experienced practitioners and educators are always on the lookout for better opportunities. One educator revealed that advanced nurses in academic institutions have the greatest opportunities to go overseas because they are often more exposed to foreign opportunities through networking. She said:

"I have lost very many well-educated nurses, especially lecturers. Such losses are irreplaceable."

\subsection{Implications for maternal health in response to the question}

"How does the availability of adequately trained nurses and midwives affect maternal health services provision in Nigeria?"

Participants indicate that the answer starts from the schools and extends to the points of care. The quality of instruction provided, the quality of nurse graduates, and the quality of care delivered to clients' impact maternal health outcome. They explained that the lack of necessary financial and technical support for nursing and midwifery education means that most classrooms are not well equipped, and instructors do not have the necessary tools to support students' learning. The instructors' readiness to provide students with solid knowledge base with which to go out and practice with confidence and improve maternal health outcomes are affected. This directly affects theoretical preparation and clinical skills training for students. In most cases, nursing students are not adequately prepared for their roles. One respondent was worried about the outcome and stated:

"When students are not well prepared for clinical practice, their care delivery skills will be compromised".

Participants indicated that despite the availability of trained nurse professionals in the job market, there are still not enough educators and clinicians that are actively employed by the system that could impact the health outcome of women, particularly in the rural areas. This simply means that large numbers of women are not accessing the necessary consultations and antenatal care they need. They cited instances where women spend an entire day in queue waiting to see a provider and could not (situations that often discourage some women from going to the health facilities in the first place). For rural clients, they fall back to the services of traditional birth attendants and other alternative providers. They were concerned that as fewer nurses handle high patient loads under difficult work environments, their care effectiveness diminishes.

\section{Discussion}

This deals with results of selected findings of the study in relationship to the answers given to the interviews conducted.

Twenty four nurses were interviewed but twenty three answered as per interview questions. This represents $95.8 \%$ of the study population respondents answered reasonably and well utilized. One person declined from answering few questions, representing $4.2 \%$. Frequency of $50 \%$ above is significant support. Selected findings from the interviewed questions are discussed below.

The result obtained from interview in respect to unemployment, poor infrastructure, less than adequate teaching and clinical work condition, and poor remuneration were consistent with findings of labiran et al; (2008), Pittman et al; (2007) that revealed there were significant effects of continuous hemorrhaging of nursing workforce thereby creating shortage of nurses' workforce within the country.

This study suggested that increasing numbers of Nigerian nurses are interested in, and actively pursuing across-the-border employment opportunities. This result also is supported by Dovlo (2007) who concurred that even minor losses of nurses to migration will magnify the existing shortage in sub-Saharan countries. Furthermore, the effect of each loss is 
significant, considering the length of time and resources it takes to train nurse and the country's high maternal and mortality rate.

Further findings from the study revealed that most nurses, who migrate internally are very high skilled clinical care professionals with several years of working experience. This is in agreement with Clemens (2010) and Hancock (2008) who also supported that experience and sophisticated nurses are the first to be targeted for recruitment from any country, as they are those that have language skills and confidence to negotiate the complex immigration procedures and processes. Findings from the above study reveal that $95 \%$ affirmed migration of nurses to other countries affect the workforce productivity as related to material mortality rate.

Delay promotion, meager salaries and inadequate compensations is identified by Kingman (2010), as this creates frustration and affect the morals and performance of nurses thereby causing them to consider alternative options; this negatively affects nurses' productivity towards reducing maternal mortality rate in the country. The future of nursing and midwifery in Nigeria might be endangered.

Dovlo (2007) Furthermore, the effect of each loss is significant, considering the length of time and resources it takes to train a nurse and the country's high maternal mortality rate. Highly educated nurse professionals such as educators and other high level practitioners are usually the first to find external opportunities.

Another finding of the study is on nursing and midwifery education, recruitment and retention which are important in pursuing efforts to improve maternal health. This is in conformity with Ezeonwu (2011) who state that staff nurse and midwives direct and provide most obstetric care more than any other providers. This study also supported Ndatsu(2011) who identified the path to higher degree is still important for Nigerian nurses; nurses urged to go through universities to obtain higher qualifications. NMCN (2010) agreed with nurses improve educational qualification for increase workforce. It emphasized that despite the slow movement towards university-based programme, and the many logistical challenges, the schools engage in strong and competent practitioners in the country. The above finding is supported by 24 respondents representing $100 \%$ of study population.

\subsection{Limitations}

A methodological limitation of this study is that the findings capture the views of a convenient rather than random sample of nurse experts. The views of experts in universitybased academic program are not so much included. Furthermore, the number of participants is small based on number of graduates in the state. However, the number is appropriate for a qualitative study that utilizes the analysis of interview texts.

\subsection{Conclusion}

Nurses are at the center of health care delivery in Nigeria. Although schools continue to produce significant number of competent nurses and midwives annually under tough conditions and with minimal resources, the system fails to absorb the graduates, resulting in high nursing unemployment. Furthermore, the push and pull factors related to global labor market forces such as poor salaries and benefits, and poor working conditions force more nurses to exit the pool. These issues result in inadequate number of nurses that are actively involved in tackling the health needs of a nation whose population continues to grow exponentially.

\subsection{Recommendation}

1. The National University Commission (NUC) should prioritize the approval of more nursing programmes at the Baccalaureate and graduates level in Nigerian universities.

2. Nursing and midwifery council of Nigeria should design curriculum for university-based programmes that could be offered for master and doctorate 
level graduates in the country.

3. The nursing and midwifery council of Nigeria should look into the subordinate role of the female nurses in relation to physicians' indoctrination in the early nursing education in the country.

4. Employers of nurses need to be considerate in boosting the morale of employees positively towards effecting promotion, increase salaries and adequate compensation.

\subsection{Summary}

Nigeria desperately needs an efficient health system that is committed to not only continued training of highly qualified nurses and midwives, but also to creating attractive well-paying jobs that could boost competitive recruitment and retention. Such efforts will help in addressing the surging maternal health needs in the country.

\section{References}

[1.] ADIKIBI, A (2009). The impact of healthcare staff migration: lessons from Nigeria's river state. Pract. Midw. 12(1):4-6. AWOFESO, N (2010). Improving health workforce recruitment and retention in rural and remote regions of Nigeria. Rural rem. Health 10:1319. BORNO STATE GOVERNMENT (2011A). Welcome to Borno state. Available at: http://www.bornostate.gov.ng/ (accessed 10 august 2014).

[2.] BORNO STATE GOVERNMENT (2011B). Overview: Location and people. Available at: http://www.bornostate.gov.ng/about-anambra.html (accessed 10 august 2014).

[3.] BULATAO RA, ROSS JA (2003). Which health services reduce maternal mortality? evidence from ratings of maternal health services. Trop. Med. Int. Health 8(8): 710-721.

[4.] BUOR D, BREAM K (2004). An analysis of the determinants of maternal mortality in sub-Saharan Africa. J. Women health (larchmt). 13(8):926-938.

[5.] CHANKOVA S, NGUYEN H, CHIPANTA D, KOMBE G, ONOJA A, OGUNGBEMI K (2006). A situation assessment of human resources in the public health sector in Nigeria: A joint government of Nigeria (fmoh/naca) and phrplus report. Available at: http://pdf.usaid.gov/pdf_docs/pnadh422.pdf (accessed 19 November 2014).

[6.] CLEMENS, MA (2010). Health worker migration: Disease or symptom? Global health. Available at: http://www.globalhealthmagazine.com/ Cover stories/health worker_migration (accessed 16 may 2012) DOVLO, D (2007). Migration of nurses from sub-Saharan Africa: a review of issues and challenges. Health serv. Res. 42(3): part ii, 1373-1388.

[7.] ELO S, KYNGAS H (2007). The qualitative content analysis process. J. Adv. Nurse. 62(1):107115. EZEONWU, MC (2011). Maternal birth outcomes: processes and challenges in Borno state, Nigeria. Health care women int. 32(6): 492-514.

[8.] FAGEN, PW (2009). The migration of health care workers in the western Hemisphere: issues and impacts. United Nations publications eclac - Studies and perspectives series. No. 7, Washington. Available at: http://www.eclac.cl/publicaciones/xml/3/38353/2009689 s7eypwas the migration of heath care workers web.pdf (accessed 12 October 2014).

[9.] GEREIN N, GREEN A, PEARSON S (2006). The implications of shortages of health professionals for maternal health in sub-saharan Africa. Reprod. Health matters 14(27):40-50.

[10.] GRANEHEIM UH, LUNDMAN B (2004). Qualitative content analysis in nursing research: concepts, procedures and measures to achieve trustworthiness. Nurse educ. Today 24:105-112.

[11.] HAGOPIAN A, OFOSU A, FATUSI A, BIRITWUM R, ESSEL A, GARY HART L, WATTS C (2005). The flight of physicians from west Africa: views of African Physicians and implications for policy. Soc. Sci. Med. 61(8):1750-1760.

[12.] HANCOCK PK (2008). Nurse migration: the effects on nursing education. int. Nurse. rev. 55:258-264. Joint learning initiative [jli] (2004).

[13.] HUMAN RESOURCES FOR HEALTH: overcoming the crisis. Available at: http://www.healthgap.org/camp/hcw_docs/jli_human_resources_for_health.pdf (accessed 16 November 2014). 
[14.] LABIRAN A, MAFE M, ONAJOLE B, LAMBO E (2008). Health resources for health country profile: Nigeria. Available at: http://www.hrh-observatory.afro.who.int/images/documentcentre/Nigeria _country_profile.pdf (accessed 20 October 2014).

[15.] MACKEY KM, LIANG BA (2012). Rebalancing brain drain: exploring resource allocation to address health worker migration and promote global health. health policy 107(1):66-73.

[16.] MUNJANJA OK, KIBUKA S, DOVLO D (2005). The nursing workforce in sub-Saharan Africa. Available at: http://www.icn.ch/images/stories/documents/publications/gnri/issue7_ssa.pdf (accessed 19 November 2014). NATIONAL BUREAU OF STATISTICS (2010). Women and men in Nigeria, 2009. Available at: http://www.nigerianstat.gov.ng/ (accessed 10 august 2014).

[17.] NATIONAL COALITION ON AFFIRMATIVE ACTION (2009). National gender policy: federal republic of Nigeria. Available at: http://www.aacoalition.org/national_policywomen.htm\#top (accessed 23 November 2014).

[18.] NATIONAL UNIVERSITIES COMMISSION [NUC] (2012). Universities: list of nigerian universities and years founded. Available at: http://www.nuc.edu.ng/pages/universities.asp (accessed 19 November 2014).

[19.] NDATSU, PN (2004). Nursing and midwifery council of Nigeria's role in maintaining standards in nursing education and practice. A paper presented at the conference of the committee of principals of schools of nursing, psychiatry and midwifery (copsnpam). Ilorin, nigeria. Available at: http://www.nmcnigeria.org/pub/paper2004.pdf (accessed 23 September 2014).

[20.] NURSING AND MIDWIFERY COUNCIL OF NIGERIA [NMCN] (2005). Nursing as a career: nursing education programs in Nigeria. Available at: http://nmenigeria.org/career.php (accessed 23 October 2014).

[21.] NURSING AND MIDWIFERY COUNCIL OF NIGERIA [NMCN] (2007). Establishment. Available at: http://www.nmenigeria.org/estab.php (accessed 7 September 2014). Nursing and midwifery council of Nigeria [nmcn] (2010). List of approved schools of nursing, midwifery, post basic nursing programmers' and departments of nursing in Nigeria and their accreditation status as at 31 st july, 2010. Available at: http://www.nmcnigeria.org/approved_schools.pdf (accessed 10 august 2014). Oladera (1996).

[22.] Nursing education and administration in Nigeria: progress and challenges . J. Nurs. admin. 26(6): 16-19.

[23.] ORUBULOYE O, ONI B (1996). Health transition research in Nigeria in the era of structural adjustment programme. Health transit. Rev. 6:301-324. PITTMAN P, FOLSOM A, BASS E, LEONHARDY K (2007). U.S-based international nurse recruitment: structure and practices of a burgeoning industry. Available at: http://www.intlnursemigration.org/assets/pdfs/report-on-year-i.pdf (accessed 11 November 2014).

[24.] POPOOLA, D (1993). Nigeria: consequences for health. In: "the impact of structural adjustment on the population of Africa: implications for education, health and employment". Heinemann, London. Post and parcel (2007). The importance of migration and remittances to economic stability and competitiveness. Available at:

http://postandparcel.info/24553/in-depth/the-importance-of-migrationand-remittances-to-economicstability-and-competitiveness/ (accessed 20 September 2014).

[25.] SHIFFMAN, J (2007). Generating political priority for maternal mortality reduction in 5 developing countries. Am. J. Publ. Health. 97(5):796-803. tache s, schillinger d (2009). Health worker migration: time for the global justice approach. Am. J. Publ. Health. 9(3):12-14.

[26.] World Health Organization [WHO] (2006). The world health report 2006-working together for health. Available at: http://www.who.int/whr/2006/en (accessed 30 September 2014).

[27.] World Health Organization [WHO] (2011). Nigeria: country Statistics. Available at: http://apps. who.int/ghodata/?vid=15000\&theme=country (accessed 19 October 2014).

[28.] World Health Organization [WHO] (2012). Who countries: Nigeria. Available at: http://www.who.int/countries/nga/en/1 